\title{
Short-Term Changes in the Numerical Density of Synapses in the Intermediate and Medial Hyperstriatum Ventrale following One-Trial Passive Avoidance Training in the Chick
}

\author{
T. P. Doubell and M. G. Stewart \\ Brain and Behaviour Research Group, Department of Biology, Open University, Walton Hall, Milton Keynes, MK7 6AA, \\ United Kingdom
}

\begin{abstract}
Previous ultrastructural studies using stereological counting techniques, based on assumptions regarding shape, size, and orientation of synapses, have suggested synaptic remodeling occurred at least $24 \mathrm{hr}$ after one-trial passive avoidance training in day-old chicks. The present study estimates the mean synaptic density $\left(N_{\mathrm{v} \text { syn }}\right)$ in a region of the chick forebrain known to be involved in memory formation, the intermediate and medial hyperstriatum ventrale (IMHV), 1 and $24 \mathrm{hr}$ following one-trial passive avoidance training. A stereological technique, the "disector," that makes no assumptions about size, shape, and orientation of synapses was used in the synaptic analyses. The density of axospinous synapses increased by approximately $77 \%$ at $1 \mathrm{hr}$ posttraining in the right IMHV of chicks (M-trained) that learned to avoid a bitter-tasting bead, compared to those (W-trained controls) that peck a water-coated bead. A measure of the postsynaptic density size, the mean projected height of synapses $(H)$, was $57 \%$ smaller $1 \mathrm{hr}$ posttraining in the right IMHV of M-trained chicks. These differences were not found at $24 \mathrm{hr}$ posttraining. We suggest that structural modification of synapses may be a key part of the processes involved in short-term memory formation.
\end{abstract}

[Key words: avian learning, memory, synapses, stereology, chick]

One-day-old chicks readily learn in a single trial to avoid pecking at a bead if it is coated with an aversive-tasting substance (Cherkin and Lee-Teng, 1965; Cherkin, 1969). This one-trial passive avoidance training task has been used in our laboratory for a number of years to study the cellular correlates of memory formation (Stewart, 1990, 1991; Rose, 1991). Following passive avoidance training, autoradiographic studies have shown that in chicks that have learned to avoid a methylanthranilate-coated chrome bead, there is enhanced incorporation of 2-deoxyglucose in two forebrain regions, the intermediate and medial hyperstriatum ventrale (IMHV) and lobus parolfactorius (LPO), compared to control chicks that have pecked a water-coated bead (Kossut and Rose, 1984). The IMHV has previously been implicated as playing a crucial role in filial imprinting (Horn, 1985),

\footnotetext{
Received June 24, 1992; revised Oct. 7, 1992; accepted Nov. 24, 1992.

We thank S. P. R. Rose and members of the BBRG for helpful comments on the manuscript, and the two referees for their helpful comments.

Correspondence should be addressed to Dr. M. G. Stewart at the above address or to T. P. Doubell, Cerebral Functions Research Group, Department of Anatomy and Developmental Biology, University College London, London WC1E 6BT, UK.

Copyright (c) 1993 Society for Neuroscience $0270-6474 / 93 / 132230-07 \$ 05.00 / 0$
}

and it also shows a variety of electrophysiological, biochemical, and morphological changes after passive avoidance training (Rose, 1991; Stewart, 1991). Furthermore, trained chicks that have tasted methylanthranilate fail to show electrophysiological and morphological differences within the IMHV compared to control chicks when rendered amnesic immediately after training with subconvulsive electroshock (Mason and Rose, 1988; Patel et al., 1988).

Quantitative ultrastructural studies have shown that passive avoidance training results in a decrease in the postsynaptic density length in the right IMHV and an increase in the number of synaptic vesicles per synapse in the left IMHV $24 \mathrm{hr}$ posttraining (Stewart ct al., 1984). Further experiments in the LPO region of chick forebrain have demonstrated a bilateral increase in synaptic density after passive avoidance training (Stewart et al., 1987). Hunter (1991) and Hunter and Stewart (1992) have shown these changes in the LPO occur over an extended time period of 24-48 $\mathrm{hr}$ posttraining.

Such changes indicate the potential for very considerable remodeling of neuronal architecture following memory formation. Indeed, the idea that synapses are labile structures and may show dynamic properties even in adult animals has been reported in several studies with mammals in vivo. Purves and Lichtman (1987) and Purves et al. (1987) have visualized nerve cells at different times in living mice and shown that following denervation the distribution of synapses on the same neuronal cell bodies was almost always different in appearance after reinnervation. In other mammalian models of neural plasticity differences in synapse density have been observed following experimental manipulations of the environment in which the animals are housed. In the rat visual cortex, $30 \mathrm{~d}$ of differential rearing (Turner and Greenough, 1985) produces increases in the synapse-to-neuron ratio and there are decreases in the density of synapses in the neuropil in layer IV of the visual cortex of dark-reared, compared to light-exposed, rats (Gabbott and Stewart, 1987). Studies on long-term potentiation (LTP), a model of synaptic plasticity, show increases in the number of shaft and sessile spine synapses $10-15 \mathrm{~min}$ after induction of LTP that persist for at least $8 \mathrm{hr}$ (Chang and Greenough, 1984) in subfield CA1 of rat hippocampal slices. Desmond and Levy (1986) have also found significant increases in the synaptic density of concave spine profiles following LTP in the rat hippocampal dentate gyrus.

Quantitative electron microscopical studies in the CNS have used stereological formulas based on assumptions about the size, shape, and orientation of synapses to estimate the number of 
synapses in a volume of tissue (numerical density) from counts of synapse profiles on two-dimensional histological sections. Such stereological methods are termed model based (Warren, 1992), one of which assumes synapses to have a simple disk shape. However, serial section analysis reveals that synapses have a complex shape (De Groot and Vrensen, 1978) that can change after training (Vrensen and Nunes-Cardoso, 1981) and exposure to different environmental conditions (Turner and Greenough, 1985). Therefore, stereological formulas that are model based may give biased estimates of synapse density due to unfulfilled assumptions in the model. Furthermore, this bias in estimating numerical density may change between experimental groups. New counting procedures such as the "disector" (Sterio, 1984; Gundersen, 1988) make no assumptions about the shape of synapses (i.e., they are said to be unbiased) and permit a more sensitive means of estimating subtle changes in synapse number (Braendgaard and Gundersen, 1986) independent of concurrent shape alterations (De Groot and Bierman, 1986; Calverley et al., 1988).

The disector can dircetly allow estimation of synapses by enabling one to count the tops or edges of synapses occurring in a volume of brain bounded by two adjacent serial sections and hence directly gives the numerical density of synapses. Using a simple counting rule, synapses are only recorded if they occur in one of the pair of serial sections and not the other. By using the disector to estimate the synaptic density an additional measure of the size of the postsynaplic density, the mean projected height, can be gained with little extra work (Calverley et al., 1988).

The present investigation makes use of the disector method to estimate the synaptic density in the IMHV 1 and $24 \mathrm{hr}$ after passive avoidance training. In addition the projected mean height of the postsynaptic density was also measured.

A preliminary communication of some of these data has been made in abstract form (Doubell and Stewart, 1992).

\section{Materials and Methods}

Training. Domestic chicks (Gallus domesticus) were hatched in communal brooders at $37^{\circ} \mathrm{C}$. At $1 \mathrm{~d}$ of age pairs of birds were taken and placed in pens $1 \mathrm{hr}$ before passive avoidance training. Each chick was presented with a white pretraining bead three times at 5 min intervals. The bead was presented $2-3 \mathrm{~cm}$ from the birds beak and the response scored as peck or avoid. After a further 10 min chicks were presented with a chrome bead coated in either an aversive substance, methylanthranilate (M-trained chicks), or water (W-control chicks), exactly as described previously (Stewart et al., 1987). Birds that exhibited a disgust response, shaking of head and wiping their beak on the cage floor, after M-training, were tested for avoidance of an identical dry chrome bead hoth at 1 and $24 \mathrm{hr}$ later. Similarly, W-trained birds were tested at the same time. Birds that gave the correct response on training and testing, that is, M-birds that avoided, and W-birds that pecked, were anesthetized and perfused.

Perfusion and fixation. Birds ( $n=32,16 \mathrm{M}$-trained and $16 \mathrm{~W}$-control) were anesthetized deeply with an intraperitoneal injection of sodium pentobarbital and then perfused transcardially with $30 \mathrm{ml}$ of $0.9 \%$ saline followed by $150 \mathrm{ml}$ of $2 \%$ paraformaldehyde, $2 \%$ glutaraldehyde fixative, both prewarmed to $37^{\circ} \mathrm{C}$. The brains were removed and placed in the same fixative overnight. The following day the IMHVs were dissected out with the aid of a brain mold (Rose and Csillag, 1985).

Microscopy. The brain tissue was prepared for electron microscopy by postfixing in $1 \%$ osmium tetroxide for $1 \mathrm{hr}$, dehydrating through graded alcohols, and embedding in Epon resin. Blocks were hardened in an oven at $70^{\circ} \mathrm{C}$ for $48 \mathrm{hr}$. One block from each hemisphere was used to estimate synapse density. Ultrathin sections of silver interference color were cut on an ultramicrotome with a diamond knife and mounted on single-slot grids coated with Formvar support film. Pairs of serial sections were mounted on the same slot grid. One section was chosen at random (the nominated section) and the adjacent section became the reference section. The first field of view was placed on a conspicuous object, for example, a mitochondrion in the top left corner of the nominated section. Fields were selected at a magnification of $2000 \times$ and photographed at $6000 \times$. The same field was then found on the reference section and photographed. The two fields represent a disector. Further disectors were chosen by moving the microscope stage controls three fields to the right and three fields to the bottom. This was continued until 20 fields on two pairs of sections had been photographed. Thus, a systematic sample of micrographs was produced and enlarged to a final magnification of $25,000 \times$. Unbiased counting frames were placed on the micrographs for synaptic counts. The bottom and left boundaries of the frame were deemed forbidden lines (Gundersen, 1977). Any synapse crossing these lines was excluded from the analysis. Synapses were counted (see Fig. 1) if they were present in the nominated section and absent in the reference section (Sterio, 1984). Identification of synapses was made on the basis of a synaptic density associated with at least three synaptic vesicles. Synapses were then classified depending on the nature of their postsynaptic density as either symmetrical (presumed inhibitory), or asymmetric (presumed excitatory) (Gray 1969). Synapses were further classified as shaft or spine depending on the postsynaptic target site. Section thickness was measured according to the Small "fold" technique (Small, 1968). Each section was scanned to find a minimal fold that was then photographed. Reliability of this method has previously been confirmed by microinterferometry (Hunter, 1989).

Calculation of mean synaptic numerical density $\left(N_{v \mathrm{syn}}\right)$ per $\mu \mathrm{m}^{3}$ was done using the following formula:

$$
N_{v \text { syn }}=\frac{\Sigma Q_{\text {syn }}^{-}}{t A},
$$

where $\Sigma \mathrm{Q}_{\mathrm{syn}}^{-}$is the total number of counted synapse profiles that appear only in the nominated section, $t$ is the section thickness, and $A$ is the area of the counting frame.

The area of the counting frame and the separation of the disector were corrected for magnification (previously checked with a grating replica, 2160 lines $/ \mathrm{mm}$ ). Separate estimates were made for morphological subtypes of synapses.

The mean projected synapse height $\left(H_{\mathrm{syn}}\right)$, a measure of the size of postsynaptic density, was calculated from

$$
H_{\mathrm{syn}}=\left(\frac{\Sigma Q_{\mathrm{syn}}}{\Sigma Q_{\mathrm{syn}}^{-}}\right) t,
$$

where $\Sigma Q_{\text {syn }}$ is the total number of synapses in the nominated and reference fields.

Estimates of synapse height $(H)$ were made from all the micrographs used in the synaptic density study, but synapses were not grouped into morphological subtypes.

All data were loaded on to a VAX mainframe computer and statistical analysis was carried out using the Minitab package. Two-way analysis of variance using a split-plot design was used to test for differences between training and hemisphere. Unpaired Student's $t$ test was used to examine differences between mean synaptic density values and projected mean height between M-trained and W-control chicks.

\section{Results}

Mean numerical density of synapses $\left(\mathrm{N}_{v \text { syn }}\right)$

The overall mean synaptic density in left and right hemispheres of trained and control chicks was $0.42 / \mu \mathrm{m}^{3}$. When this was considered in terms of the density of the two major classes of synapses (asymmetric and symmetric), 97\% were asymmetric and only $3 \%$ were symmetric. The value for symmetrical synapses varied very little from this $3 \%$ level between control and trained chicks. Therefore, the statistical analysis of electron micrographs from trained and control chicks is presented here only for the asymmetric synapse population. However, a further analysis of the asymmetric synapse population was made in which they were classified as shaft or spine depending on the postsynaptic target. In this case the numbers of the relative proportions 

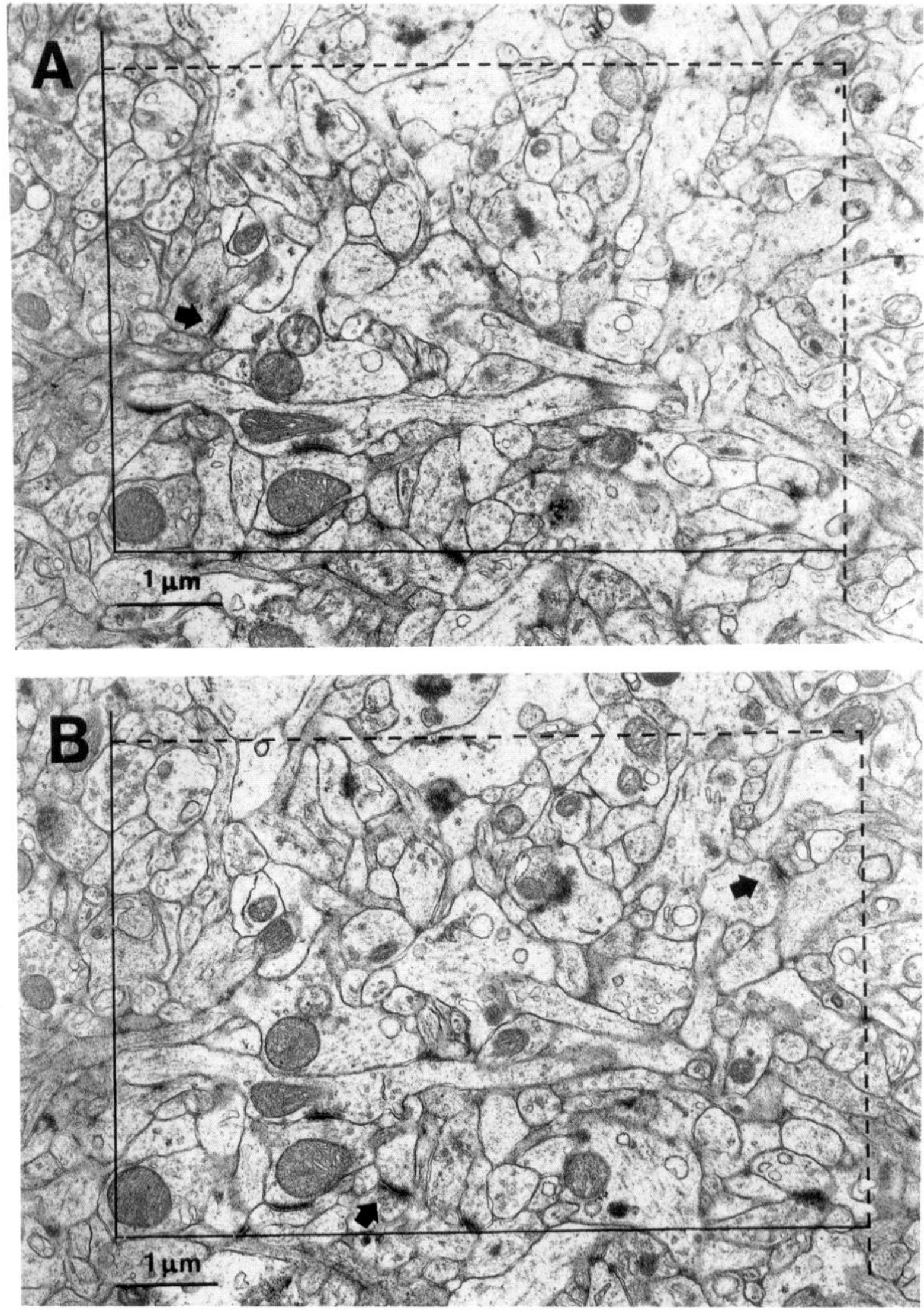

Figure 1. Synapses are selected using a three-dimensional probe, the "disector," in which micrographs of the same fields of view $(A, B)$ are taken from two parallel adjacent ultrathin sections separated by a distance of $68 \mathrm{~nm}$. Synapses are counted (arrows) if they appear within the counting frame or if they touch the dashed frame border of $A$ (nominated section) but are absent from field $B$ (reference section) and vice versa, forming a second disector. The number of synapses from the two disectors $(3 / 2$, i.e., 1.5$)$ occur in a volume given by the product of the counting frame area and distance between the sections. The numerical density of synapses is calculated from $N_{v \text { syn }}=\Sigma Q_{\text {syn }}^{-} / t A$. 


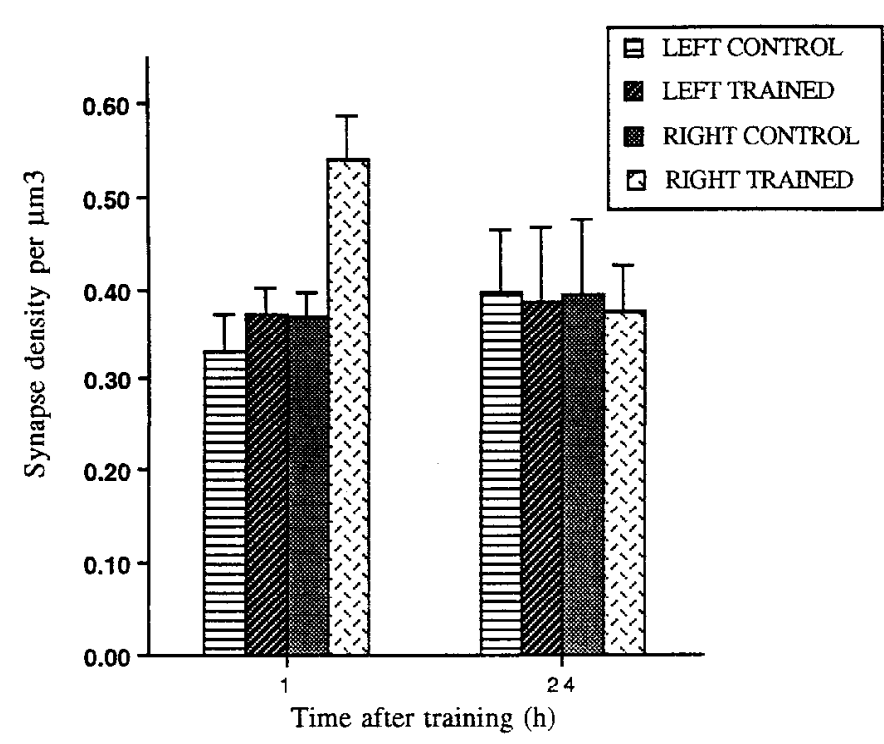

Figure 2. Mean numerical density of asymmetrical synapses (spine and shaft combined) in the left and right hemispheres IMHV of control and trained chicks 1 and $24 \mathrm{hr}$ after passive avoidance training. Error bars represent the SEM of eight M-trained and eight W-control chicks. There is a $46 \%$ increase in asymmetrical synapse density at $1 \mathrm{hr}$ posttraining between the right hemispheres of $\mathrm{M}$ - and $\mathrm{W}$-trained chicks that is significant at $p<0.002$.

of the two classes were more even; $54 \%$ of the synapses (in trained and control chicks combined) are of the asymmetric shaft type whereas $46 \%$ are asymmetric spine synapses. Therefore, the synaptic density estimates presented here also classify asymmetric synapses depending on their postsynaptic location, that is, whether on spines or on dendritic shafts.

\section{Asymmetric synaptic density changes following avoidance training}

Overall changes. The numerical density of asymmetric spine synapses in left and right hemispheres of trained and control chicks at 1 and $24 \mathrm{hr}$ posttraining is shown in Figure 2. A splitplot ANOVA (examining for training and hemisphere differences) shows that there is a significant training effect, an increase in synaptic density in $\mathrm{M}$-trained chicks compared to W-control birds at $1 \mathrm{hr}$ posttraining $\left(F_{1,14}=5.59, p<0.025\right)$. In addition, there was a significant hemispheric asymmetry in synaptic density $\left(F_{1,14}=5.16, p<0.031\right)$. When left and right hemispheres were tested separately for a training effect with a Student's $t$ test, only the right hemisphere showed a significant increase $(46 \%)$ in synaptic density $(t=3.79, \mathrm{df}=14, p<0.002)$, whereas in the left hemisphere the increase following training (13\%) is not significant. When the data in Figure 2 at $24 \mathrm{hr}$ posttraining were tested by an ANOVA, there were no significant training or hemisphere differences between M-trained and W-control chicks.

Changes in asymmetric spine synapses. The data for asymmetric spine synaptic density in left and right hemispheres at 1 and $24 \mathrm{hr}$ posttraining, and in hemispheres of control chicks at this time are shown in Figure 3. These demonstrate a pattern of results that are essentially similar to those for overall asymmetric synapse density in Figure 2 . At $1 \mathrm{hr}$ posttraining the density of asymmetric spine synapses was significantly increased in M-trained chicks compared to W-control chicks at $1 \mathrm{hr}\left(F_{\mathrm{l}, 14}\right.$ $=7.65, p<0.010$ ). This is due to a $77 \%$ increase in synaptic density in the right hemisphere of trained compared to the right

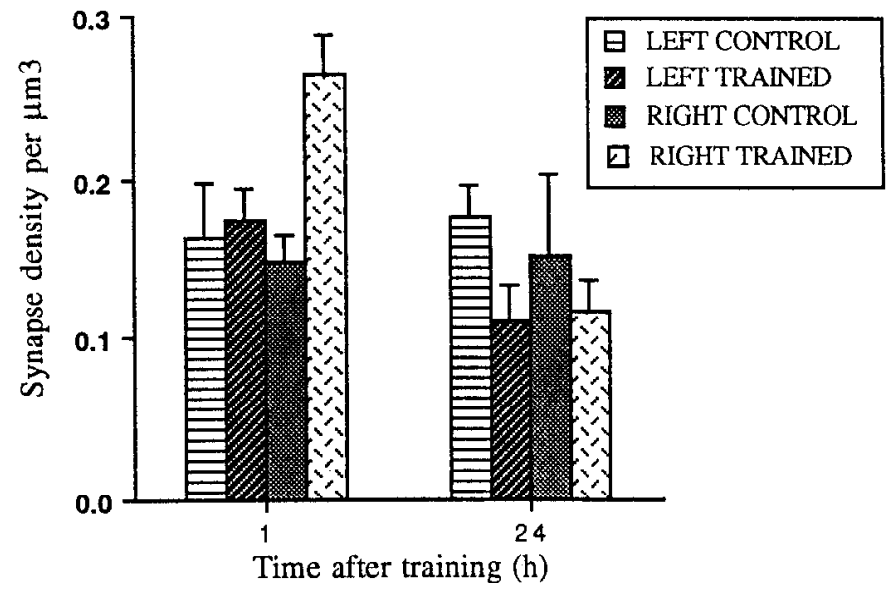

Figure 3. Mean numerical density of asymmetric spine synapses in the left and right hemisphere IMHV of control and trained chicks 1 and $24 \mathrm{hr}$ after passive avoidance training. Error bars represent the SEM of eight $\mathrm{M}$-trained and eight $\mathrm{W}$-control chicks. There is a $77 \%$ increase in asymmetric spine synapse density in the right hemisphere at $1 \mathrm{hr}$ posttraining in trained compared to control chicks. Differences are significant at $p<0.002$.

hemisphere of control birds, and when the differences between left and right hemispheres were tested separately for a training effect with a Student's $t$ test only the right hemisphere showed a significant increase $(t=3.79, \mathrm{df}=14, p<0.002)$.

Asymmetric shaft density measurements. There was no significant training effect on asymmetric shaft synapse density at the $1 \mathrm{hr}$ time point (Fig. 4) $\left(F_{\mathrm{l} .14}=1.33\right.$, NS). However, there was a significant hemispheric asymmetry present, with a higher shaft synapse density in the right hemispheres compared to the left hemisphere of both W-control and M-trained chicks ( $F_{1,14}$ $=4.46, p<0.044)$. No significant differences for asymmetric spine or shaft synapses were found between trained and control chicks at $24 \mathrm{hr}$ posttraining.

\section{Mean projected synaptic height $\left(\mathrm{H}_{s y n}\right)$ of all synapses in the IMHV}

One hour after avoidance training the $\mathrm{M}$-trained chicks have a significantly smaller synaptic height (i.e., size) than W-control chicks (Fig. 5) $\left(F_{1,14}=9.487, p<0.005\right)$. When tested separately only the right hemisphere differences between trained and control chicks were significant (approximately 57\% smaller in trained birds) $(t-2.6, \mathrm{df}-14, p<0.021)$. There were no significant differences of projected height between M-trained and W-control chicks at $24 \mathrm{hr}$.

\section{Discussion}

The main findings of the present study are that $1 \mathrm{hr}$ after onetrial avoidance learning there is a large and highly significant increase in the numerical density of asymmetric spine synapses in the right IMHV of trained compared to control birds. In addition there is a significant decrease in the size (measured as synaptic height) of the synapses measured in the right hemisphere at this time. The differences between trained and control chicks, in both synaptic number and synaptic size, disappear by $24 \mathrm{hr}$ posttraining. This evidence suggests that during the initial phase of memory formation after passive avoidance learning, transient structural changes are required involving synapse formation, but by $24 \mathrm{hr}$ posttraining the transicnt incrcasc is absent, because either synapses have been eliminated or tissue volume 


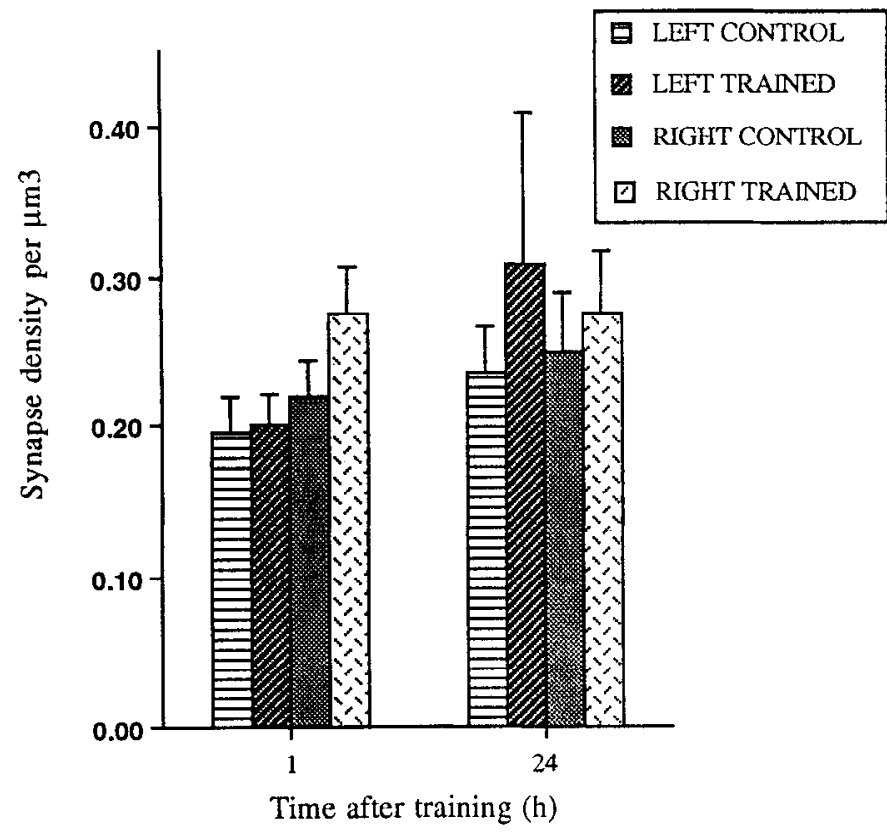

Figure 4. Mean numerical density of asymmetric shaft synapses in the left and right hemisphere IMHV of control and trained chicks 1 and 24 $\mathrm{hr}$ after passive avoidance training. The effect of training on the numerical density of asymmetric shaft synapses is not significant. Error bars represent the SEM of eight M-trained and eight W-control chicks.

changes have occurred to alter the measured synaptic density. These alternative possibilities are discussed further below.

Previous experiments demonstrated that metabolic, neurophysiological, and morphological changes occur in the IMHV and LPO after passive avoidance training (Rose, 1991; Stewart 1991). They also report differences between the times of involvement of the IMHV and LPO in recall for the passive avoidance rcsponsc. Unilatcral pretraining lesions of the left IMHV, but not right, cause amnesia whereas as early as $1 \mathrm{hr}$ posttraining similar lesions have no effect on retention (Patterson et al., 1990). Bilateral lesions of the LPO only impair memory retention when given posttraining and not pretraining (Gilbert et al., 1991). The left IMHV is thus involved in memory acquisition, and it has been suggested that memory flows from the left to the right IMHV, and then bilaterally to the LPO. However, contrary to earlier expectations (Patterson and Rose, 1989), the IMHV does play a role in memory posttraining because Patterson and Rose (1992) have shown that, in chicks given bilateral IMHV lesions posttraining, the ability for color discrimination is lost. Moreover, there is evidence from several pharmacological studies that the right IMHV is important in memory formation. Intracranial injections of $N$-nitro-arginine, an inhibitor of the synthesis of nitric oxide (a putative retrograde messenger involved in maintenance of LTP), causes amnesia for the passive avoidance task when injected into either the left or the right IMHV (L. C. Holscher and S. P. R. Rose, unpublished observations). There appears to be a complex interrelationship between the IMHV and the LPO in memory formation and storage (Patterson and Rose, 1992) that reflects the fact that representations of even the simple association of a bead with an aversive taste are based on different classificatory clues that are thus multiple and located in widely different brain regions.

IMHV and I PO show synaptic density increases, mainly confined to the asymmetric spine synapses in M-trained chicks

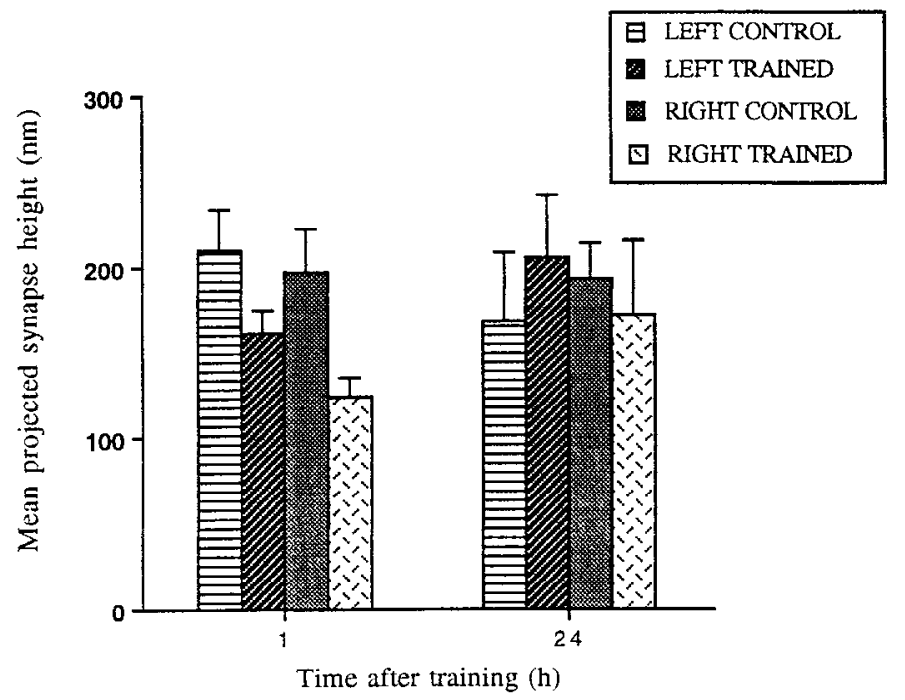

Figure 5. Mean projected height (i.e., size) of all classes of synapse in the left and right hemisphere IMHV 1 and $24 \mathrm{hr}$ after passive avoidance training. Error bars represent the SEM of eight M-trained and eight $\mathrm{W}$-control chicks. The difference at $1 \mathrm{hr}$ posttraining (a $57 \%$ decrease in size) between the right hemispheres of $M$ - and W-trained chicks is significant at $p<0.02$, whereas at $24 \mathrm{hr}$ posttraining this difference has been lost.

compared to W-control chicks following passive avoidance training. The present study has shown that the IMHV synapse density increases within the first hour after training but is absent $24 \mathrm{hr}$ posttraining. The absence of synaptic increases at 12 and $24 \mathrm{hr}$ has also been shown previously by Bradley and Galal (1987) and at $24 \mathrm{hr}$ posttraining by Stewart et al. (1984). It is unlikely that such a rapid increase in the synapse density is due to a reduction in the volume of the IMHV and therefore probably represents an increase in the number of synapses. The loss of differences in spine synapse density in the IMHV between trained and control groups at the later time of $24 \mathrm{hr}$ posttraining may indicate either that spine synapse elimination occurs, or that there is change in the volume of the surrounding neuropil in the intervening $23 \mathrm{hr}$ such that there is a decrease in synaptic density.

Selective elimination of synapses has been suggested as a mechanism for learning by Changeux and Danchin (1976), who suggested that synaptogenesis occurs before the acquisition of new behaviors and after learning synapse elimination occurs as some pathways and synapses are stabilized and preserved the expense of others. However, in the present case the apparent transient increase in synaptic number in the right IMHV appears to occur as a result of learning and is more likely to be related in some way to a short-term aspect of information processing in the IMHV, possibly connected with information flow to the main memory storage site of the chick forebrain described above, the LPO. After this has occurred the apparent increase in synaptic number disappears either by synapse elimination or due to change in neuropil volume. Change in the volume of the neuropil could occur via alterations in glial cell size and/or capillary volume, as have been reported in the cortex of rats raised in enriched compared to impoverished environments (Greenough et al., 1990, 1991). But given that no changes in volume occur in the LPO (Hunter, 1991) at the 24 hr time point posttraining this would require changes alone in IMHV volume, which seems unlikely since the overall volume of the chick 
forebrain does not change significantly at $24 \mathrm{hr}$ posttraining in trained compared to control chicks. However, in the absence of measurements of glial cell, blood vasculature, and extracellular space of the IMHV $24 \mathrm{hr}$ posttraining, we cannot rule out the possibility that such changes contribute at least in part to the decline in synaptic number at this time in trained chicks.

If synaptogenesis has occurred, it is not possible to say whether the new synapses formed in trained chicks are consolidated and a different set of synapses are eliminated or that newly formed synapses are transient. It is interesting to note that the decrease in size of the synaptic height occurs concomitantly with the increase in synaptic number, which is suggestive of a process of splitting of preexisting synapses, as proposed by Greenough (1984) and Calverley and Jones (1990). This process is believed to occur at synaptic membrane perforations, and although these are seldom seen in control or trained chicks synapse, splitting may occur at the thinner parts of the synaptic membrane that are present. It is interesting that the size of the synapses (as measured by synaptic height) is similar in trained and control chicks at $24 \mathrm{hr}$ posttraining, indicating cither enlargement of the smaller synapses seen in trained chicks at $1 \mathrm{hr}$ posttraining, or that a portion of the smaller size classes has been eliminated.

Structural changes at the synaptic connections have been widely postulated as a basis for learning and memory (Greenough and Bailey, 1988). Changes in synaptic density have been shown to occur after extended periods of differential rearing (Turner and Greenough, 1985), and after long-term sensitization of Aplysia sensory neurons (Bailey and Chen, 1989). Increases in number of synapses are assumed to play a role in long-lasting memory storage because they occur several or more hours after training, a time by which synthetic processes involved in synaptic growth or remodeling could have occurred. In the case of synaptic changes in Aplysia, Bailey and Chen (1989) have showed these to persist for 3 weeks. Our studies reveal that following passive avoidance training a new morphological process has occurred involving only short-term transicnt changes in numbers of spinc synapses.

While our data are novel, in reporting such a rapid change in synaptic density due to learning of a behavioral task, other workers have shown that changes in synaptic number can occur very quickly after various types of experimental manipulation. Studies on hippocampal LTP indicate that synapses can be formed and lost within minutes (Chang and Greenough, 1984; Desmond and Levy, 1986). Chang and Greenough (1984) showed increased numbers of shaft and sessile spine synapses after 10$15 \mathrm{~min}$ that persist for at least $8 \mathrm{hr}$ following LTP in rat hippocampal CAI subfield. Neither of these studies (Chang and Greenough, 1984; Desmond and Levy, 1986) show any significant changes in the total synaptic density, and it is not clear if the morphological changes (approximately $7 \%$ of the total synapse population) observed following LTP are responsible for the enhancement of the EPSP. The observed changes following LTP may represent an interconversion of synaptic types. During synapse development it has been suggested that shaft synapses are first formed and then converted to spine synapses (Mates and Lund, 1981; Miller and Peters, 1981). The higher total synaptic density in the IMHV of trained versus control birds following avoidance learning must represent formation of new synapses, although interconversion of shafts to spines synapses cannot be ruled out.

Few studies have reported such rapid changes in synapses apart from those following LTP. Since LTP does not involve memory formation per se, it is an important question whether synapses can form quickly enough to mediate short-term memory following learning paradigms. Recently, it has been reported that rapid synaptogenesis occurs in the rat occipital cortex $1 \mathrm{hr}$ after administration of the glutamate agonist NMDA (Brookes et al., 1991). However, the mechanism of any such short-term synaptic changes remains unknown. Future experiments should help elucidate a possible mechanism for short-term morphological changes at synapses and their role in memory formation.

\section{References}

Bailey CH, Chen M (1990) Morphological alterations at identified sensory neuron synapses during long-term sensitization in Aplysia. In: Symposia Medica Hoechst 23, The biology of memory (Squire LR, Lindenlaub E, eds), pp 135-158. Stuttgart: Shattauer.

Bradley PM, Galal KM (1987) The effects of protein synthesis inhibition on structural changes associated with learning in the chick. Dev Brain Res 37:267-276.

Braendgaard H, Gundersen HJG (1986) The impact of recent stereological advances on quantitative studies of the nervous system. $\mathrm{J}$ Neurosci Methods 18:39-78.

Brookes WJ, Petit TL, LeBoutillier JC, Lo R (1991) Rapid alteration of synaptic number and post synaptic thickening length by NMDA: an electron microscope study in the occipital cortex of postnatal rats. Synapse $8: 41-48$.

Calverley RKS, Jones DG (1990) Contributions of dendritic spines and perforated synapses to synaptic plasticity. Brain Res Rev 15:215249.

Calverley RKS, Bedi KS, Jones DG (1988) Estimation of the numerical density of synapses in rat neocortex: comparison of the 'disector' with an 'unfolding' method. J Neurosci Methods 23:195-205.

Chang FLF, Greenough WT (1984) Transient and enduring morphological correlates of synaptic activity and efficacy change in the rat hippocampal slice. Brain Res 309:35-46.

Changeux JP, Danchin A (1976) Selective stabilisation of developing synapses as a mechanism for the specification of neuronal networks. Nature 264:705-712.

Cherkin A (1969) Kinetics of memory consolidation: role of amnestic treatment parameters. Proc Natl Acad Sci USA 63:1094-1101.

Cherkin A, Lee-Teng E (1965) Interruption by halophane of memory consolidation in chicks. Fed Proc 24:328.

Curtis EM, Stewart MG, King TS (1989) Quantitation of synaptic, neuronal and glial development in the intermediate and medial hyperstriatum ventrale (IMHV) of the chick Gallus domesticus, pre- and post-hatch. Dev Brain Res 48:105-118.

De Groot DMG, Bierman PB (1986) A critical evaluation of methods for estimating the numerical density of synapses. J Neurosci Methods 18:79-101

De Groot DMG, Vrensen G (1978) Post-natal development of synaptic contact zones in the visual cortex of rabbits. Brain Res 147: 362-369.

Desmond NL, Levy WB (1986) Changes in the numerical density of synaptic contacts with long-term potentiation in the hippocampal dentate gyrus. J Comp Neurol 253:466-475.

Doubell TP, Stewart MG (1992) Synaptic density increases in the intermediate and medial hyperstriatum ventrale of the chick, one hour after passive avoidance training. Neurosci Lett [Suppl] 42:S42

Gabbott PLA, Stewart MG (1987) Quantitative morphological effects of dark-rearing and light exposure on the synaptic connectivity of layer IV in the rat visual cortex (area 17). Exp Brain Res 68:103-114.

Gilbert DB, Patterson TA, Ruse SPR (1991) Dissociation of brain sites necessary for registration and storage of memory for a one-trial passive avoidance task in the chick. Behav Neurosci 105:553-561.

Gray EG (1969) Electron microscopy of excitatory and inhibitory synapses. In: Progress in brain research, Vol 31, Mechanisms of synaptic transmission (Akert J, Waser PG, eds), pp 141-155. Amsterdam: Elsevier.

Greenough WT, Bailey CH (1988) The anatomy of a memory: convergence of results across a diversity of tests. Trends Neurosci 11: $142-146$.

Greenough WT, Withers GS, Wallace CS (1990) Morphological changes in the nervous system arising from behavioural experience: what is the evidence that they are involved in learning and memory? In: 
Symposia Medica Hoechst 23, The biology of memory (Squire LR, Lindenlaub E, eds), pp 159-192. Stuttgart: Shattauer.

Greenough WT, Alcantara A, Hawrylak N, Anderson BA (1991) Determinants of brain readiness for action: experience shapes more than neuronal form. Brain Dysfunct 4:33.

Gundersen HJG (1977) Notes on the estimation of the numerical density of arbitrary profiles: the edge effect. J Microsc (Oxf) 111:219223.

Gundersen HJG (1988) The new stereological tools. APMIS 96:379$394,857-881$.

Horn G (1985) Memory, imprinting and the brain. An enquiry into mechanisms. Oxford: Clarendon.

Hunter A (1991) Synaptic plasticity in the chick lobus parolfactorius during development and following memory formation. PhD thesis, Open University, UK.

Hunter A, Stewart MG (1993) Long-term increases in the numerical density of synapses in chick lobus parolfactorius after passive avoidance training. Brain Res, in press.

Kossut M, Rose SPR (1984) Differential 2-deoxyglucose uptake in the chick brain structures during passive avoidance training. Neuroscience 12:971-977.

Mason RJ, Rose SPR (1988) Passive avoidance learning produces focal elevation of bursting activity in the chick brain: amnesia abolishes the increase. Behav Neural Biol 49:280-292.

Mates SL, Lund JS (1983) Spine formation and maturation of type 1 synapses on spiny stellate neuron in primate visual cortex. J Comp Neurol 221:91-97.

Miller M, Peters A (1981) Maturation of rat visual cortex 2: a combined Golgi-electron microscope study of pyramidal neurons. J Comp Neurol 203:555-573.

Patel SN, Rose SPR, Stewart MG (1988) Training induced spine density changes are specifically related to memory formation processes in the chick, Gallus domesticus. Brain Res 463:168-173.

Patterson TA, Rose SPR (1992) Memory in the chick: multiple cues, distinct brain locations. Behav Neurosci 106:465-470.

Patterson TA, Gilbert DB, Rose SPR (1990) Pre- and post-training lesions of the intermediate medial hyperstriatum ventrale and passive avoidance learning in the chick. Exp Brain Res 80:189-195.

Purves D, Lichtman JW (1987) Synaptic sites on reinnervated nerve cells visualized at two different times in living mice. J Neurosci 7:14921497.
Purves D, Voyvodic JT, Magrassi L, Yawo H (1987) Nerve terminal remodelling visualized in living mice by repeated examination of the same neuron. Science 238:1122-1126.

Rose SPR (1991) Biochemical mechanisms involved in memory formation in the chick. In: Neural and behavioural plasticity: the use of the domestic chick as a model (Andrew RJ, ed), pp 277-304. Oxford: Oxford UP.

Rose SPR, Csillag A (1985) Passive avoidance training results in lasting changes in 2-deoxyglucose metabolism in the left hemisphere regions of chick brain. Behav Neural Biol 44:315-324.

Small JV (1968) Measurement of section thickness. In: Proceedings of the 4th European Congress on Electron Microscopy, Vol 1 (Bocciarclli DS, cd), p 609. Rome: Tipografia Poliglotta Vaticana.

Sterio DC (1984) The unbiased estimation of number and size of arbitrary particles using the disector. J Microsc (Oxf) 134:127-136.

Stewart MG (1990) Morphological correlates of long-term memory formation in the chick forebrain consequent on passive avoidance learning. In: Symposia Medica Hoechst 23, The biology of memory (Squire LR, Lindenlaub E, eds), pp 193-220. Stuttgart: Shattauer.

Stewart MG (1991) Changes in dendritic and synaptic structure in chick forebrain consequent on passive avoidance learning. In: Neural and behavioural plasticity: the use of the domestic chick as a model (Andrew RJ, ed), pp 305-328. Oxford: Oxford UP.

Stewart MG, Rose SPR, King TS, Gabbott PLA, Bourne R (1984) Hemispherical asymmetry of synapses in chick medial hyperstriatum ventrale following passive avoidance training: a stereological investigation. Dev Brain Res 12:261-269.

Stewart MG, Csillag A, Rose SPR (1987) Alterations in synaptic structure in the paleostriatal complex of the domestic chick, Gallus domesticus following passive avoidance training. Brain Res 426:69-81.

Turner AM, Greenough WT (1985) Differential rearing effects of rat visual cortex synapses. 1 . Synaptic and neuronal density and synapse per neuron. Brain Res 329:195-203.

Vrensen G, Nunes-Cardoso J (1981) Changes in size and shape of synaptic connections after visual training: an ultrastructural approach to synaptic plasticity. Brain Res 218:79-97.

Warren A (1992) Simple morphometry of the nervous system. In: Quantitative methods in neuroanatomy (Stewart MG, ed), pp 211247. Chichester: Wiley. 